\title{
Method of temperature measurement in cutting zone while turning using portable class thermal imaging system
}

\author{
Anukhin I.V. \\ IMMET \\ SPbSPU \\ St. Petersburg, Russia \\ ivan.anuhin@mail.ru \\ Lyubomudrov S.A. \\ IMMET \\ $S P b S P U$ \\ St. Petersburg, Russia \\ Lyubomudrow@yandex.ru
}

\author{
Anukhin V.I. \\ IMMET \\ $S P b S P U$ \\ St. Petersburg, Russia \\ victoranuhin@mail.ru \\ Nikitkov N.V. \\ IMMET \\ $S P b S P U$ \\ St. Petersburg, Russia \\ nnvnvi@mail.ru
}

\begin{abstract}
The article offers a method for temperature measurement in the cutting zone on a turning lathe. Application of thermal imager BALTECH TR-01500 allowed one to record the thermogramm of the cutter running out from the cutting zone at the moment of releasing the cutter face from chips. The values of the coefficients of thermal emissivity of the cutter and chips were recorded in the memory of the thermal imager.
\end{abstract}

The article presents the conclusion of dependence of difference of mechanical characteristics of the machining material and the material of the cutter on heating temperature and the determination of the optimal temperature of cutting. There is a description of the method of temperature measurement and a photo of installation, also there is a frameby-frame thermogramm of the cutter running out from the cutting zone and temperature changing of the external surface of the chip and the cutter face. The calculation of error of measurement of temperature of the cutter face was presented.

Keywords-thermal imager, temperature, thermogramm, cutter, metal chips, coefficient of thermal emissivity, turning lathe.

\section{INTRODUCTION}

In conditions of high pressures and temperatures, operating in the machine components of the modern special quality stainless steels, wear-resistant and heat-resistant steels and alloys become more and more widespread. While metal cutting such materials, the cutting power of cutting tools often does not exceed $3 . . .10$ minutes.

The primary target in metalworking of such materials and alloys is the selection of cutting tools in plant conditions, of its geometry and cutting parameters, in which the cutting tool wear would be minimal, and the machining quality is acceptable.

The method of rapid determination of optimal cutting conditions, wherein intensity of cutting tool dimensional wear will be minimal, proposed by A.D. Markov, nowadays with the advent of new steels and alloys is particularly important

This method is based on regularity of constancy of optimum cutting temperature found by A.D. Makarov [5]. He was found that each pair "work material - material of cutting tool" has one optimum cutting temperature (conform the minimum intensity dimensional wear), and does not depend on various combinations of cutting speed, feed, depth of cut and geometrical parameters of the cutting tool.

It has been hypothesized that cutting tool's rate of wear is proportional of the hardness difference of the cutting and processing material at a certain temperature in the cutting zone. The more is the difference of hardness of the cutting and processed materials, the lower the rate of wear.

\section{MATERIALS AND METHODS}

Based on the research of hardness of processing materials and materials of cutting tools, depending on the heating temperature, the following dependence was determined:

$$
\frac{d H R C}{d \theta}=-\alpha \cdot\left(H R C-H R C_{H}\right) \text {, }
$$

where $H R C$ - the hardness of the material at a temperature of $\Theta^{\circ}, \mathrm{GPa}$; $\mathrm{GPa}$;

$H R C_{H}$ - the hardness of the material at room temperature, $\alpha$ - the coefficient of proportionality.

As a result of integrating the differential equation with separable variables, the following congruence is obtained:

$$
\ln \frac{H R C-H R C_{H}}{H R C_{0}-H R C_{H}}=-\alpha=\left(\theta_{0}-\theta\right), H R C \neq H R C_{H},
$$


where $\Theta_{0}$ - temperature, for which the hardness of present material $H R C_{0}$ is close to zero, meaning the impossibility of this material to resist any impact.

Transforming the obtained equation, regarding that $H R C_{0}=0$ , we get:

$$
H R C=H R C_{H}\left[1-e^{-\alpha\left(\theta_{0}-\theta\right)}\right]
$$

After obtaining characteristics of an alteration in hardness of the process and cutting material due to a temperature action in a working area, it is possible to determine the dependence of the alteration in hardness difference on the temperature. Then we can find such temperature in the working area that provides the minimal cutting tool wear for the pair of materials under consideration.

Let us assign index «1» to the material of the cutting tool and index « $2 »$ to the material of the billet and find the difference:

$H R C_{1}-H R C_{2}=H R C_{H 1}\left(1-e^{-\alpha_{1}\left(\theta_{01}-\theta\right)}\right)-H R C_{H 2}\left(1-e^{-\alpha_{2}\left(\theta_{02}-\theta\right)}\right)$ $\left.H R C_{1}-H R C_{2}=\left(H R C_{H 1}-H R C_{H 2}\right)+H R C_{H 2} e^{-\alpha_{2}\left(\theta_{02}-\theta\right)}-H R C_{H 1} e^{-\alpha_{1}\left(\theta_{01}-\theta\right)}\right)$

Hereupon let us define the temperature for which found difference will take a maximal value. We shall take a $\Theta$ derivative of difference and, equating it to zero, obtain an equation:

$$
\alpha_{2} H R C_{H 2} e^{-\alpha_{2}\left(\theta_{02}-\theta\right)}=\alpha_{1} H R C_{H 1} e^{-\alpha_{1}\left(\theta_{01}-\theta\right)} .
$$

Let us solve it for $\Theta$ and find an expression for optimal cutting temperature for definite pair of materials:

$$
\theta=\frac{\ln \frac{\alpha_{2}}{\alpha_{1}}+\ln \frac{H R C_{H 1}}{H R C_{H 2}}-\alpha_{2} \theta_{02}+\alpha_{1} \theta_{01}}{\alpha_{1}-\alpha_{2}}
$$

As a check on a preliminary proposition and implementation of a method of accelerated cutting mode optimization under production conditions, a reliable, accurate and handy way of temperature measurement in the cutting area is required.

From numerous ways of cutting temperature measurement, it is possible to distinguish following: calorimeter method, thermocolor method, measurement of temperature using thermocouples, dynamic thermocouple method, method of metal chips upper surface temperature measurement.

The analysis of existing methods of temperature measurement in the cutting area revealed that neither of listed methods unfit for the application task of accelerated cutting mode optimization under production conditions.

There are some common disadvantages of listed methods, such as:

1. A considerable error of temperature measurement as a result of the measurement out of the cutting area, and also the influence of a large number of factors, including size of the toolholder and tool extension [3-5] etc.

2. For the purpose of increasing the accuracy of temperature measurement in the cutting area, there's a necessity for additional experiments to create mathematical models of heat flows in the cutting area [6]. The calculation of the temperature in the cutting zone is carried out on the basis of models of heat flows on the obtained values of temperatures near this area [7].

3. Application of the method of temperature measurement in the cutting area with the help of thermocouples assumes special cutter's design or significant changes, such as drilling holes for thermocouples in the working part of the cutter. The use of cutters with replaceable cutting inserts essentially eliminates such cutter rework, or causes to install thermocouple under replaceable cutting inserts, which significantly reduces the accuracy of measurement and complicates the application of the method in the production conditions.

At the Department "Technology of mechanical engineering" SPbSPU for testing method of accelerationextended definition of optimum machining rate in production conditions was suggested to use the method of temperature measuring in the cutting zone with thermal imaging system.

Temperature measuring with the thermal imaging system has a variety of advantages.

1. The thermal imaging system allows obtaining thermogramms, which can determine temperature distribution in a given area, and also allows one to determine in the most heated zone in the monitoring area and to measure its temperature with sufficient accuracy. For example, the measurement error may not exceed $\pm 2{ }^{\circ} \mathrm{C}$.

2. Using of thermal imaging system does not impose restrictions on the construction of cutting tools, accessories and machines.

The usage of the thermal imaging system for temperature measuring in the cutting zone at the same time have some limitations.

1. The measuring result is influenced by the emissivity of measured object. Emissivity coefficient may range from 0.02 to 0.98 , by a factor of 50 times [1], [2], and its value depends on:

- material of the object;

- the temperature of the heated area;

- the color and condition of the surface of an object, for example, the outer surface of a chip rougher and heater than a smooth inner surface. According to results of our measurements, emissivity coefficient of outer surface of titanium chips (rough surface) is equal to 0.6, internal and adjacent to the cutter (smooth surface), - 0,2..0,35;

- the appearance of thin metal oxide on the surface of the chip and the cutter face impairs the accuracy of test indications.

2. The cutting zone while turning is closed by chips, and it is possible to define the temperature of the front surface of the cutter only on the external surface of the chip. The results of temperature measurement in the cutting zone will be underrated because of the presence of a substantially different temperature gradients, see Fig. 1.

To avoid these constraints of temperature measurement the portable thermal imaging system BALTECH TR-01500 was 
chosen, it allows one to film objects with a frame rate of 50 $\mathrm{Hz}$ with simultaneous fixing of the temperature field and measuring the maximum temperature of the object. The range of measurements of the thermal imager is from $-20^{\circ} \mathrm{C}$ up to $1800^{\circ} \mathrm{C}$, with measurement error $\pm 2^{\circ} \mathrm{C}$. The thermal imager allows one to correct coefficients of thermal emissivity from $0,01 \ldots 1,0$, remembers their values and displays zones representing the temperature field with allowance for various coefficients of thermal emissivity.

Thus, it is possible to measure the temperature of the chip at the moment of its formation with a reduction rating the coefficient of thermal emissivity of external surface of the chip in a time of the cutter's run out from the cutting area and releasing the cutter's face from the chips to determine the maximum temperature of the cutter face, with its coefficient of thermal emissivity.

An experimental installation on the basis of turning lathe model 16B16KA was created.

The work piece ring of titanium alloy VT1-0 of $135 \mathrm{~mm}$ in diameter with machined riffles for the cutter's run out from the cutting area was installed on the turning lathe. Turning section's length was determined by timing out of the cutting process on the stationary thermal conditions, which is determined on the outer surface of the chip in the area of its formation. Fig. 2 shows the time of running out cutting process on the stationary operating condition.

Two zones are clearly visible In Fig. 2: in the first zone \#1 maximum chips temperature is measured at a sufficient distance from its formation, (the temperature of the chip is $149.9^{\circ} \mathrm{C}$ ) and second zone - \#3, which covers almost the whole screen, measures the maximum temperature in the area of chip's forming $-175,8^{\circ} \mathrm{C}$. Later on, the temperature in the chip's formation zone will slightly change.

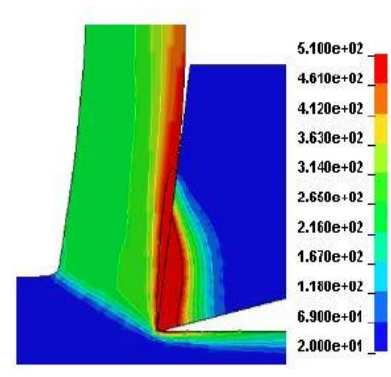

Fig. 1. Temperature distribution in the main secant plane

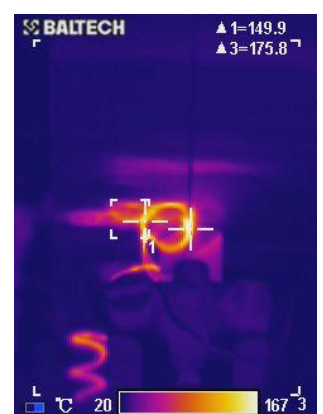

Fig. 2. Example of temperature measuring of external surface of chip with thermal imaging system
The determination of thermal emission coefficients was carried out while heating titanium alloy chip and cutter. To avoid impact on the thermal emission coefficient during the machining of oxides and irregularities on the cutter face, the cutter worked on this titanium alloy for a short time.

Cutter and chips were maintained until full heating in a muffle furnace, heated to the certain temperature. The temperature of heating was measured by two exemplary thermocouples (maximum temperature measuring error $1^{\circ} \mathrm{C}$ ). A film was made. Thermal emission coefficient of the cutter face near its top and external surface of a chip was established.

Determination of the coefficients was carried out at a temperature of $250^{\circ} \mathrm{C}$ for the external surface of the chip, which was established for zone 3 , and at a temperature of $550^{\circ} \mathrm{C}$ - for the cutter face, which is attached to zone 1 . The value of coefficients stored in memory of the thermal imager. In the thermal imager two zones with different thermal emission coefficients of radiation was established. While shooting process of machining, zone 1 and 3 overlapped, temperature measuring was carried out simultaneously with different thermal emission coefficients. While cutter is running out from the cutting zone, temperature of a cutter face and external surface of the chip were recorded without distortion.

The work piece ring from titanium alloy VT1-0 with riffles was machining with bar blade plates from hard alloy VK8 without plating. The corners of sharpening cutter are: face angle $\gamma=0^{\circ}$, clearance angle $\alpha=8^{\circ}$, entering angle $\varphi=45^{\circ}$, end cutting edge angle is $\varphi_{1}=15^{\circ}$. Cutting conditions are: cutting velocity $\mathrm{v}=100 \mathrm{~m} / \mathrm{min}$, cutter feed $\mathrm{s}=0.15 \mathrm{~mm} / \mathrm{rev}$, cutting depth $\mathrm{t}=0.5 \mathrm{~mm}$.

Regular shooting of cutting zone by the thermal imager BALTECH TR-01500 (Fig.3) allows one to fix the moment of cutter running out from wok piece and to define the temperature field of the cutter face with simultaneous fixing of temperature of the external surface of the chip, see Fig. 4. The evaluation was carried out according to, in advance of a certain limited, coefficient emissivity chips $-0,6$ and cutter face $-0,12$

\section{The portable thermal imaging system The work piece ring}

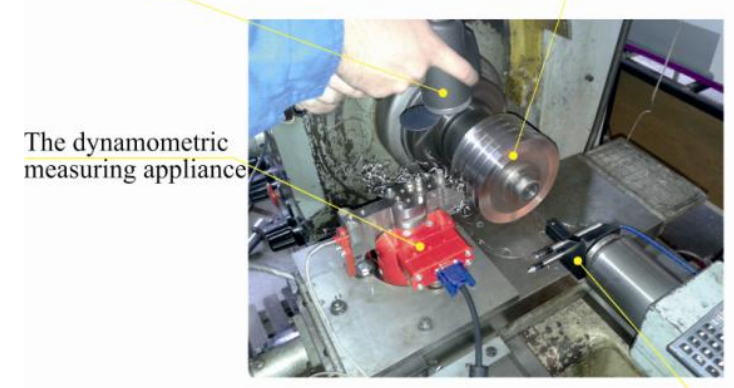

The measuring device of dimension cutter wear

Fig. 3. Temperature measuring of the external surface of the chip and the cutter face at the experimental arrangement 

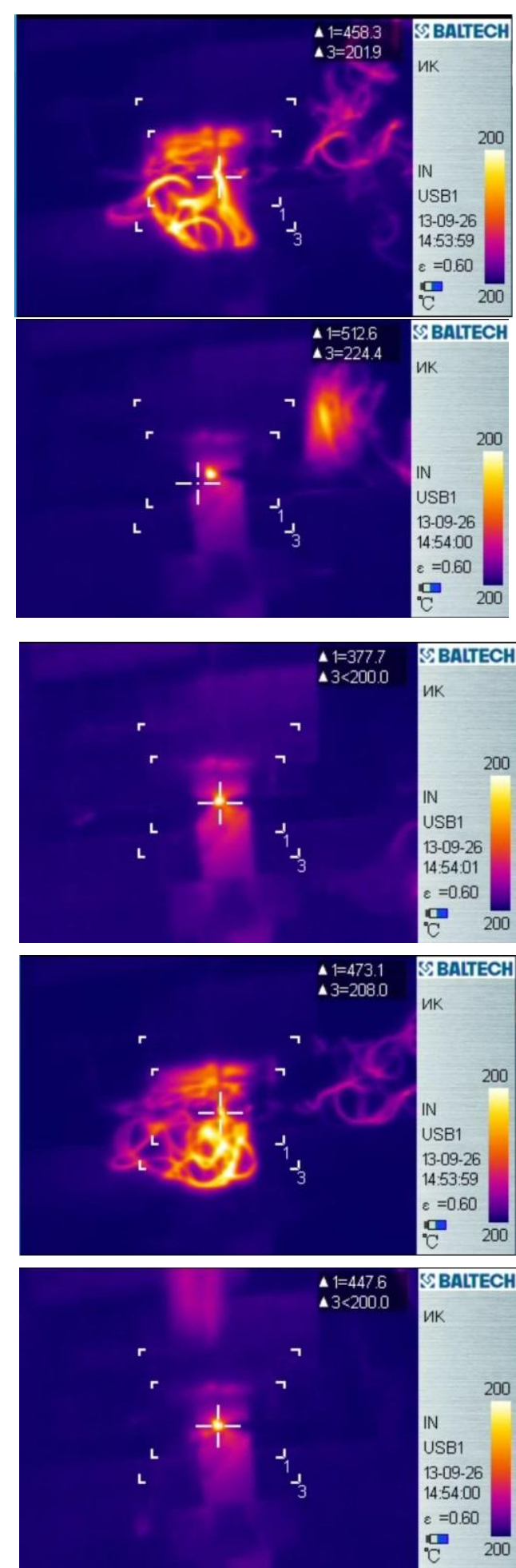

0.62s. before releasing the cutter from metal chips. Time: 02-53p.m. 59.78s.

Time of clearing out the cutter from metal chips.

Time: $\quad 02-54$ p.m. 00.40s.

$0.62 \mathrm{~s}$, the cutter is cooling down.

Time: 02-54p.m. $01.02 \mathrm{~s}$

0.42 s. before releasing the cutter from metal chips. Time: 02-53p.m. $59.98 \mathrm{~s}$

$0.21 \mathrm{~s}$., the cutter is cooling down.

Time: 02-54p.m. $00.61 \mathrm{~s}$

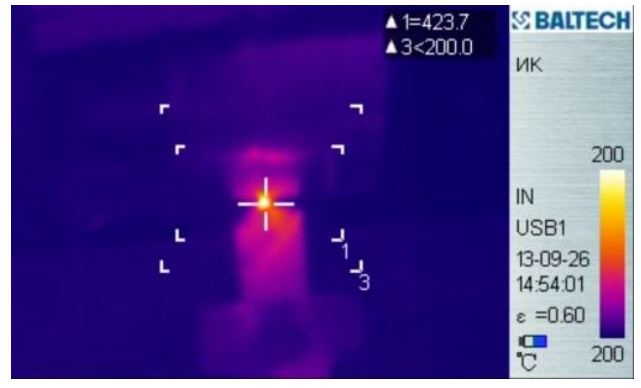

$0.81 \mathrm{~s} .$, the cutter is cooling down.

Time: 02-54p.m. $01.21 \mathrm{~s}$.

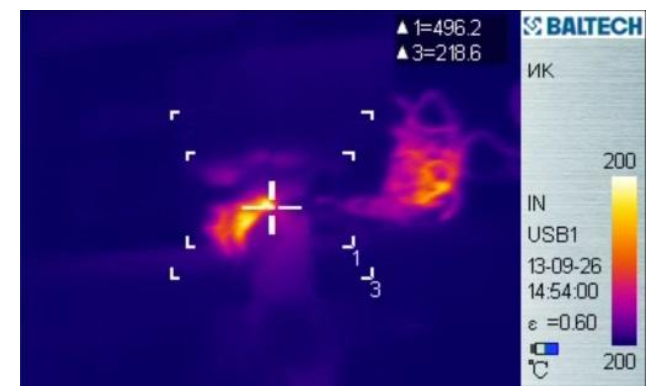

0.21 s. before releasing the cutter from metal chips. Time: $02-54$ p.m. $00.19 \mathrm{~s}$

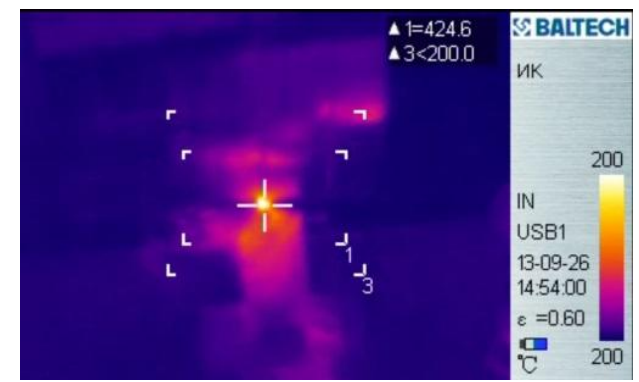

$0.41 \mathrm{~s}$, the cutter is cooling down

Time: 02-54p.m. $00.81 \mathrm{~s}$

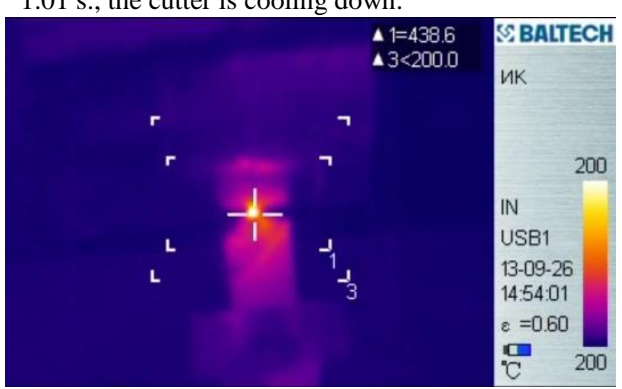

Time: 02-54p.m. 01.42s.

Fig. 4. Frame thermogramm of the running out the cutter from the work piece

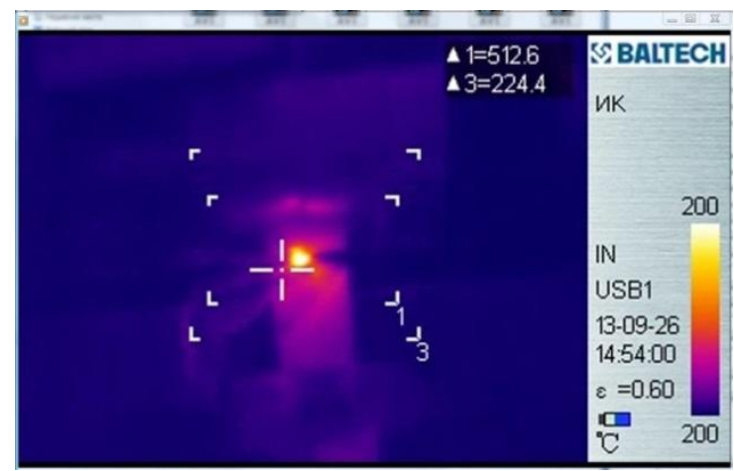

Fig. 5. Moment when the cutter runs out from the cutting zone

Figure 5 shows clearly the temperature of the cutter face at the time of its running out from a cutting zone at $512,6{ }^{\circ} \mathrm{C}$. 
After data processing of the temperature, the log was an obtained schedule, which is presented in Fig. 6.

After conducting a series of experiments, it was found that with the growth of tool wear the temperature on the external surface of a chip and the cutter face is increasing by $5 \ldots 8^{\circ} \mathrm{C}$ per $\mathrm{km}$. The cooling rate of the cutter face in the initial period of time depends on the size of the toolholder and the value of running out of the cutter and in average was $\xi=300^{\circ} \mathrm{C} / \mathrm{s}$.

The cooling rate of the cutter face in the initial period of time depends on the size of the toolholder and the value of running out of the cutter and in average was $\xi=300^{\circ} \mathrm{C} / \mathrm{s}$.

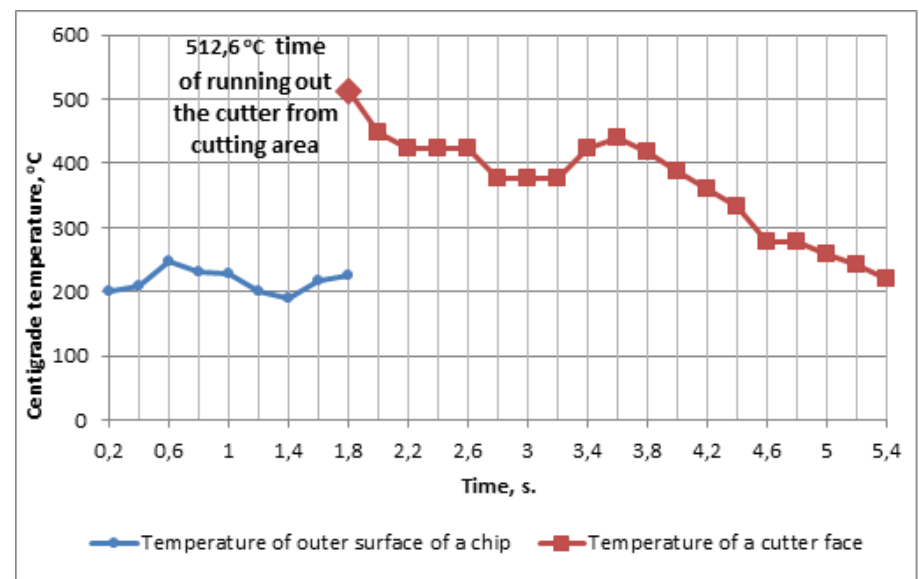

Fig. 6. Temperature changing on the external surface of a chip and a cutter face at the time of it running out from metal.

\section{CONCLUSION}

The main components of inaccuracy of measuring instrument of the cutter face were: 1. The dispersion of the results of temperature measurement of a thermal imager (according to the passport data), $a=4^{\circ} \mathrm{C}$. It is assumed that dispersion of the results of a thermal imager follows the law of equal probability. Root-mean-square assigned error of thermal imager [8] measurement in this case is:

$$
\sigma_{\mathrm{T}}=\sqrt{\int_{-0,5}^{0,5}(\mathrm{ax})^{2}} d x=1,155^{\circ} \mathrm{C} .
$$

2. The error in the determination of the coefficients of thermal emission consists of a root-mean-square assigned error of thermal imager measurement and root-mean-square error of temperature measurement of the cutter in a muffle furnace with a standard thermocouples, $\sigma_{t c}=0,289^{\circ} \mathrm{C}$. Rootmean-square estimation of emissivity coefficient:

$$
\sigma_{d}=\sqrt{\sigma_{t c}^{2}+\sigma_{t}^{2}}=\sqrt{0,289^{2}+1,155^{2}}=1,191^{\circ} \mathrm{C} .
$$

3. The value of error due to the discreteness when shooting process with frequency $\mathrm{f}=50$ frames per second. The meansquare-error that occurs when fixing the time of running out of the cutter from the cutting zone was [8]:

$$
\sigma_{x}=\sqrt{\int_{-0,5}^{0,5}(b \mathrm{x})^{2}} d x=1,732^{\circ} \mathrm{C}
$$

where $b$ - the discreteness of temperature readout the time of running out of the cutter from the cutting zone:

$$
b=\frac{\xi}{f}=\frac{300}{50}=6{ }^{\circ} \mathrm{C} / \text { frame }
$$

The total root-mean-square error of measurement:

$$
\sigma_{\Sigma}=\sqrt{\sigma_{t}^{2}+\sigma_{d}^{2}+\sigma_{\mathrm{s}}^{2}}=\sqrt{1,155^{2}+1,191^{2}+1,732^{2}}=2,40^{\circ} \mathrm{C}
$$

\section{References}

[1] G. Sutter , L. Faure, A.Molinari, "An experimental technique for the measurement of temperature fields for the orthogonal cutting in high speed machining," Int. J. of Machine tools \& Manufacture, Vol. 43, pp. $671-678,2003$.

[2] R. Carvalho, S.M.M. Lima e Silva, A.R. Machado, G. Guimaraes, "Temperature determination at the chip-tool interface using an inverse thermal model considering the tool and tool holder," Mat. Proc. Techn., Vol. 179, pp. 97-104, 2006.

[3] G.I. Granovskij, Rezanie metallov, M.: Vysshaja shkola, 1985

[4] Je.L. Zhukov, I.I. Kozar', Tehnologija mashinostroenija v 2-h knigah. Grif MO RF., izd. Vysshaja shkola, 2008.

[5] A.D.Makarov, Optimizacija processov rezanija M. : Mashinostroenie. 1976, 278 p.

[6] D.V. Krivoruchko, V.A, Zaloga , N.P. Mazur, "Analiz sovremennyh metodov chislennogo modelirovanija teplovyh javlenij pri rezanii materialov" Suchasni tehnologiï u ma-shinobuduvanni, zbirnik naukovih prac'. -H.: NTU «HPI», 2007, Vol. 3, p. 158-167.

[7] Sabhi Zantur, V.A. Boguslavskij, T.G. Ivchenko, "Optimizacija rezhimov rezanija pri tochenii trudnoobrabatyvaemyh materialov $\mathrm{s}$ uchetom temperaturnyh ogranichenij," DonNTU, Istochnik: Progresivni tehnologiï i sistemi mashinobuduvannja: Mizhnarodnij zb.naukovih prac'. - Donec'k: DonNTU, 2010, Vol. 39, 228 p.

[8] Dzh. Bendat, A. Pirsol, Izmerenie i analiz sluchajnyh processov, M.: izd. «Mir», 1971, 408 p. 